\title{
The use of morphological and histological features as nutritional condition indices of Pagrus pagrus larvae
}

\author{
Marina Vera Diaz ${ }^{1}$, María Felisa Arano ${ }^{2}$, Marcelo Pájaro ${ }^{1}$, Eddie Oscar Aristizábal ${ }^{1}$ and \\ Gustavo Javier Macchi ${ }^{1,3}$
}

\begin{abstract}
Morphometrical and histological techniques were employed to characterize Pagrus pagrus larvae nutritional condition. Larvae were reared in laboratory under controlled conditions with the main objective of testing whether these methodologies allowed finding differences between larvae from different feeding treatments. Once yolk was consumed (three days after hatching) larvae were assigned to a feeding treatment: starved during the whole experiment; delayed feeding, starved during three days; fed during the entire experiment. Algae (Nannochloropsis oculata) and rotifers (Brachionus plicatilis) were provided to larvae for feed treatments. Larvae were fixed daily; for morphometrical purposes in $5 \%$ formaldehyde solution, and in Bouin for histological sections. Results herein obtained showed that both methodologies are sensitive enough to distinguish larvae characterized by different nutritional condition states obtained from the feeding treatments. Consequently, these methodologies could be employed in wild red porgy larvae in order to asses their nutritional condition. These techniques could also be employed to check larval quality obtained with aquaculture purposes to estimate the effects of changes in rearing protocols or kind of food supply and thus, to guaranty a higher survival of early developmental stages of reared larvae.

Con el objeto de determinar si las técnicas morfométricas e histológicas permiten diferenciar larvas en estado de inanición de las sometidas a tratamientos de alimentación, ejemplares de Pagrus pagrus fueron criados en laboratorio bajo condiciones controladas. Una vez que el vitelo fue consumido (tres días luego de la eclosión) las larvas fueron sometidas a diferentes tratamientos de alimentación: completamente privadas de alimento, privadas de alimento durante tres días y luego alimentadas, y alimentadas durante todo el experimento. Algas (Nannochloropsis oculata) y rotíferos (Brachionus plicatilis) fueron proporcionados a las larvas de los tratamientos de alimentación. Diariamente se fijaron ejemplares de los tres tratamientos en formol 5\% para estudios morfométricos y en Bouin para estudios histológicos. Los resultados obtenidos dan evidencias de que las metodologías presentadas son suficientemente sensibles para determinar diferencias en la condición de larvas sometidas a los tratamientos de alimentación. Por lo tanto, podrían ser empleadas para determinar la condición nutricional de las larvas de besugo recolectadas en el mar. Por otra parte, éstas metodologías podrían ser empleadas para determinar la calidad de larvas producidas en acuicultura y evaluar los efectos de modificaciones introducidas en los protocolos de crianza o en el tipo de alimento suministrado con el objeto de mejorar la supervivencia de los estadios tempranos de desarrollo.
\end{abstract}

Key words: Critical period, Larvae histology, Larvae morphometry, Red porgy, Starvation.

\section{Introduction}

Most important causes of larval mortality are predation and starvation. The latter can be assessed by the measurement of the nutritional condition. Different criteria have been developed to assess nutritional condition of fish larvae based on the differences that starvation produces in body form (Ehrlich et al., 1976; Theilacker, 1978; Powell \& Chester, 1985; Frank \& McRuer, 1989), condition factor (Ehrlich et al., 1976), chemical cell constituents (Håkanson, 1989; Clemmesen et al., 1997) and histological integrity (O'Connell, 1976; Theilacker, 1978; McFadzen et al., 1997). From these methodologies, morphometrical and histological analysis are simple and easy to assess, and could be employed to evaluate the incidence of starvation in the ocean. These processes do not require a special preparation of the specimens and have been employed in several studies (Theilacker, 1978; Powell \& Chester, 1985; Dou et al., 2002; Kailasam et al., 2007; Bustos \& Silva, 2011; Diaz et al.,

${ }^{1}$ Instituto Nacional de Investigación y Desarrollo Pesquero (INIDEP), Paseo V. Ocampo Nro.1, Escollera Norte, Mar del Plata, B7602HSA, Buenos Aires, Argentina. mdiaz@inidep.edu.ar (MVD), mpajaro@inidep.edu.ar (MP), eddie@inidep.edu.ar (EOA), gmacchi@inidep.edu.ar (GJM)

${ }^{2}$ Universidad Nacional de Mar del Plata (UNMdP), Funes 3350, Mar del Plata, B7602AYL, Buenos Aires, Argentina

${ }^{3}$ Consejo Nacional de Investigaciones Científicas y Técnicas (CONICET), Av. Rivadavia 1917, Ciudad Autónoma de Buenos Aires, C1033AAJ, Buenos Aires, Argentina. marisaarano@hotmail.com (MFA) 
2011). Enclosure studies are essential to calibrate nutritional condition in order to determine with certainty the status of field collected specimens which nutritional condition is unknown (Hunter, 1981; Uriarte \& Balbontín, 1987).

Several studies have been successfully carried out employing morphometrical variables to assess nutritional condition of reared larvae. McGurk (1985), using herring larvae, showed that length/weight relationship and multivariate analysis of morphometrical variables are successful to classify larvae according to their nutritional condition. Moreover, Powell \& Chester (1985) employed discriminant analysis on Leiostomus xanthurus larvae reared under different feeding treatments, to assign a nutritional status to field-caught larvae of this species.

It is clear that morphometrical attributes are easily obtained and that show changes in starving larvae. However, there are some doubts about the validity of extrapolations of results obtained in laboratory experiments to wild conditions; since some differences in body proportions have been observed between reared and sea-caught individuals (Ferron \& Leggett, 1994). In that concern, histological criteria employed to assess larval nutritional condition, which involve cellular aspect and tissular integrity diagnostic, are more reliable to make comparisons between reared and ocean-caught larvae (O'Connell, 1976). The microscopical organization of target tissues and organs generally used to assess the nutritional condition of fish larvae has been deeply reviewed by Catalan (2003) and Gisbert et al. (2008).

Not all organs and tissues react to starvation in the same way and in the same sequence. Only those tissues that show changes in laboratory studies and in the ocean as well, and which clearly define different larval nutritional condition statuses without overlapping, are of use in separating well fed from short and long term starving larvae (Sieg, 1998). Some studies demonstrated that only two tissues showed clear histological changes in the lab and in situ during starvation, those are liver and gut (Ferron \& Leggett, 1994; Sieg, 1998). However, in order to give a broad approach, we analyzed histological condition employing other tissues additionally to gut and accessory glands: nervous system, cartilage, muscle, and notochord.

The red porgy (Pagrus pagrus L. 1758) is a demersal marine fish widely distributed along the Mediterranean and the western and eastern coasts of the Atlantic Ocean (Manooch, 1976; Vassilopoulou \& Papaconstantinou, 1992; Harris \& McGovern, 1997). This species contributes significantly to commercial fishing in Argentina (Cotrina, 1989; Cotrina \& Raimondo, 1997) and is considered of great potential for aquaculture diversification (Pajuelo \& Lorenzo, 1996; Maragoudaki et al., 1999; Suzer et al., 2007; Schuchardt et al., 2008). Even though several studies on development of red porgy have been carried out, as far as we know, there are no previous studies on larval condition of this species. Thus, this work represents the first approach to the subject employing $P$. pagrus larvae.

The main objective of the present work was the employment of conventional and simple methods, such as morphometrics and histology, to assess nutritional condition of red porgy larvae reared under different feeding treatments. We aimed to test whether these methodologies are sensitive enough to distinguish larvae characterized by different nutritional status.

Results of the present work are essential to calibrate nutritional condition in order to determine with certainty the status of field collected specimens which nutritional condition is unknown. Also, this information could be performed routinely to estimate the effects of changes in rearing protocols or quality of food supplied and thus, to guaranty higher survival of early developmental stages of larvae obtained for aquaculture purposes.

\section{Material and Methods}

Larval source. Adult red porgy were caught in coastal waters of Buenos Aires Province, Argentina, and were placed in an indoor fiberglass tank of $16 \mathrm{~m}^{3}$ at the experimental facilities of INIDEP, the National Institute for Fisheries Research, Argentina. Larvae herein employed came from spontaneous spawning of these breeders kept in captivity. Eggs were collected during austral summer spawning (December 2005 - March 2006) with a small net and transferred to a conical fiberglass tank of $0.1 \mathrm{~m}^{3}$ during incubation. Newly hatched larvae were randomly assigned to a feeding treatment and transferred to conical fiberglass tanks of $0.05 \mathrm{~m}^{3}$ with an initial density of 30 larvae $^{-1}$. During the period of experimentation, water temperature was kept at $18.0 \pm 0.5^{\circ} \mathrm{C}$ and the salinity ranged from 33 to 34 . Photoperiod was 12 D:12 L. In all treatments, green water containing Nannochloropsis oculata was supplied to the rearing tanks every morning to achieve an approximate concentration of 300,000 cells mll$^{-1}$. The experiment started three days after hatching (DAH) when larval yolk reserves were depleted and mouth opening took place. Three experimental feeding designs by triplicate were used: T1 starved during the whole experiment; $\mathrm{T} 2$ delayed feeding, starved during three days; $\mathrm{T} 3$ fed during the entire experiment. T0 indicate initial larval situation, before the experiment begins three DAH. Larvae from feed treatments were fed with enriched rotifers (Brachionus plicatilis) from three DAH. Rotifer density was maintained at 10 $20 \mathrm{ml}^{-1}$. Feeding scheme was adapted from the methodology presented by Watanabe \& Kiron (1996) according to Aristizábal \& Suárez(2006).

The experiment was terminated $11 \mathrm{DAH}$, two days after larvae from starved experiment showed a massive mortality.

Larvae from the three treatments were fixed daily; for morphometrical purposes in 5\% formaldehyde solution, and in Bouin for histological sections.

Morphometrics. Standard length (SL), head depth (HD), body depth at the anus (BDA) and eye diameter (ED) were recorded $\left(\mathrm{N}=246 ; \mathrm{N}_{\mathrm{T} 0}=20, \mathrm{~N}_{\mathrm{T} 1}=64, \mathrm{~N}_{\mathrm{T} 2}=80, \mathrm{~N}_{\mathrm{T} 3}=82\right)$. Measurements were made to the nearest $0.01 \mu \mathrm{m}$ using a Carl Zeiss stereoscope equipped with Axio Vision softaware. SL was taken from the tip of the snout to the end of the notochord. Measurements were made a few months after samplings in order to allow larvae to shrink. No shrinkage corrections were made since only larvae from a restricted size range were employed.

A Principal Component Analysis (PCA) was used to determine if morphological differences could be detected 
among larvae from the three feeding treatments. Analyses were performed on larvae ranged from 2 to $4 \mathrm{~mm}$ SL using Infostat ${ }^{\circledR}$ as statistical software. In order to remove the effect of size, morphometric variables employed in the PCA were normalized according to Lleonart, Salat \& Torres (2000) and Catalán (2003) to a reference length of $3 \mathrm{~mm}$ SL.

Histology. Standard histological techniques were employed in order to prepare $P$. pagrus larvae histological sections. Larvae were dehydrated in ethanol, cleared in xilol and embedded in Paraplast $\AA\left(\mathrm{N}=69 ; \mathrm{N}_{\mathrm{T} 0}=3, \mathrm{~N}_{\mathrm{T} 1}=17, \mathrm{~N}_{\mathrm{T} 2}=26, \mathrm{~N}_{\mathrm{T} 3}=23\right)$. Sagital sections of $4 \mu \mathrm{m}$ thick were mounted and stained with Harris's hematoxylin and eosin counterstain (H-E). Diagnosed tissues to calculate a Histological Condition Index (HCI) were: gut, liver, pancreas, nervous system (encephalon), cartilage (jaws and gill arches), muscle (trunk musculature), and notochord.

The histological conditions were established based on criteria used by O'Connell (1976) for Engraulis mordax and Sieg (1998) for E. anchoita, since the tissular characteristics and alterations were similar to those described for other species (O’Connell, 1976; Sieg, 1998; Theilacker, 1978; Yúfera et al., 1993; McFadzen et al., 1997). Multiple sections were examined to assess the degree of alteration throughout the specimen and each selected tissue variable assigned to one of three grades. According to Diaz (2010), several features of each tissue were diagnosed. Grade three indicated healthy, two intermediate and one a degraded histological condition. After scoring all the tissues, a mean ICH was calculated for each larva.

Additionally, diagnosed tissues were divided into short and long-term indices. This grouping responds to the different response time displayed by each tissue in several species reared in the laboratory (Kashuba \& Mathews, 1984; Theilacker, 1986). Therefore, a short term HCI was calculated employing gut, liver and pancreas and a long term HCI considering the remaining tissues. Larvae were coded to exclude personal bias in the histological diagnostics by knowing treatment of provenance.

Differences among $\mathrm{HCI}$ of larvae from feeding treatments were determined through ANOVA followed by Tukey's Honestly Significant Difference test. Due to the reduced number of samples, data did not meet ANOVA assumptions of normal distribution and homogeneous variances, but it is generally agreed that the ANOVA is robust against violations of these assumptions. Nevertheless, complementary, we performed a nonparametric Kruskal-Wallis test followed by multiple comparisons.

\section{Results}

Morphometrics. Mouth opening took place at three DAH in coincidence with the exhaustion of yolk reserves; at that moment the experiment begun. Larvae from $\mathrm{T} 3$ where fed since three DAH and food was provided to larvae from $\mathrm{T} 2$ since six DAH (indicated with arrows in Fig. 1). Nine days after hatching starved larvae from $\mathrm{T} 1$ showed a massive mortality. Two days later, the experiment ended on the $11^{\text {th }}$ day of larval life of $\mathrm{T} 2$ and $\mathrm{T} 3$.
Body depth showed a conspicuous decrease at three DAH (Fig. 1). Morphometrical variables showed an increase from four DAH in larvae from fed and starved treatments in comparison with the corresponding measurements obtained during the previous day. Fed larvae from T3 showed an increase in all the variables measured. On the contrary, starved larvae from $\mathrm{T} 1$ showed a reduction in morphometrical variables until nine $\mathrm{DAH}$ when variables reach minimal values and a mass mortality occurred.

Larvae from delayed feeding treatment (T2) showed reduction in body depth and no changes in head depth until food was supplied when variables started to increase. Length and eye diameter showed a continuous increase up to the end of the experiment. At $11 \mathrm{DAH}$ all morphometrical variables from T2 larvae showed lower values than those measured to larvae from T3 indicating a partial recovery from the starvation they suffered.

The variable that showed more sensibility to starvation was body depth since it showed the higher percentage of reduction (17.6\%) between four and nine DAH in starved larvae (Table 1). Delayed fed larvae showed an $8 \%$ of reduction in body depth within this period. The remaining variables, measured in T2 and T3 larvae, showed increased values. Body depth of larvae from T2 did not show an increase until $11 \mathrm{DAH}$, when it was $12 \%$ higher than the corresponding to four DAH. Thus, BDA turn out to be sensitive enough to show intermediate condition or recovery from starvation.

Multivariate analyses were performed on variables normalized to a reference length of three $\mathrm{mm} \mathrm{SL}$. The first two principal components of the PCA explained $91 \%$ of total variance (Table 2). PC1 explained the $75 \%$ of total variance and represented the overall pattern of the morphometric indices; it could be interpreted as an index of body condition. Though all indices were correlated to PC1, HD and BDA were most closely related with it. PC2 explained the $16 \%$ of total variance and most of this variance was explained by opposite trends between ED and BDA (Table 2).

The PCA did not show a clear separation of larvae from any of the feeding treatments, showing an important individual variability of larvae condition (Fig. 2a). This variability was also enlarged because daily sampled larvae from different feeding treatments were plotted altogether. However, when observations were grouped by feeding treatment (Fig. 2b), larvae from fed treatment (T3) where characterized by higher body depths; variable that indicate a better nutritional condition. Therefore, starved larvae (T1) exhibited slender bodies than larvae from fed treatment (T3) and delayed feeding larvae (T2) showed an intermediate situation.

Histology. Most conspicuous histological differences between larvae from different treatments were those related with gut, liver and pancreas (Fig. 3). Fed larvae were characterized by a continuous and uninterrupted intestinal mucosa. Enterocytes were wide and a distinct brush border composed of microvilli was evident. Also, cytoplasmatic vesicles and vacuoles were observed (Fig. 3a), delayed fed larvae have mucosal cells 

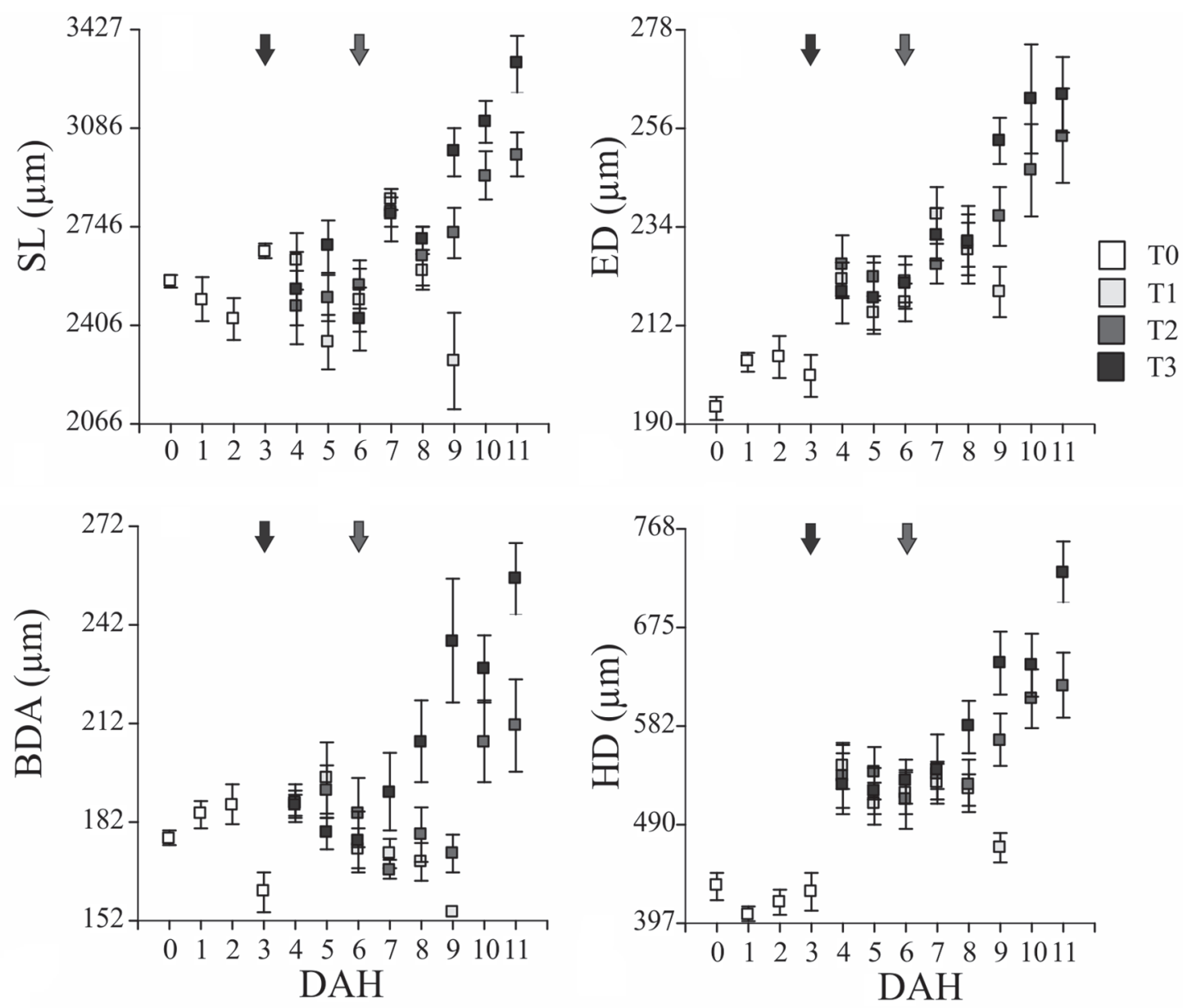

Fig. 1. Mean values of morphometrical variables and standard error against larval age expressed as days after hatching (DAH) of Pagrus pagrus larvae from the different feeding treatments. BDA: body depth at the anus, ED: eye diameter, HD: head depth, SL: standard length. T0: before the experiment begins, T1: without food, T2: delayed feeding and T3: fed. Arrows indicate the moment when food was supplied to larvae in T3 (black) and T2 (dark grey). Initial condition of larvae (T0, white squares) was also included in order to allow comparisons.

reduced in height; some loss of striations in bordering microvilli (Fig. 3b) and starved larvae showed a discontinuous intestinal mucosa, with irregular cells and intercellular spacing. Enterocytes were shrunken and mucosal height resulted considerably reduced (Fig. 3c). Fed larvae also had well structured pancreas and pancreatic cells with prominent nucleus and nucleolus (Fig. 3d), delayed fed larvae showed less proportion of pancreatic cells with prominent nucleus (Fig. $3 e)$ and pancreatic tissues of starved larvae were disrupted, with cells reduced in size and heavily stained (Fig. 3f). Hepatic tissue of fed larvae was compact and continuous. Hepatocytes showed vacuolar inclusions and prominent central nucleus (Fig. $3 \mathrm{~g}$ ), delayed fed larvae showed less proportion of hepatocytes with prominent nucleus (Fig. 3h) and starved larvae hepatic tissue was fractioned with wide intercellular spaces. The cytoplasm was reduced, without vacuolar spaces and irregular deeply stained nucleus (Fig. 3i).
Fed larvae encephalon was compact with associated cells (Fig. 4a), delayed fed larvae showed a slight dissociation with intercellular spaces (Fig. 4b) and starved larvae showed wide intercellular spaces (Fig. 4c). Cartilage of fed larvae were characterized by large and prominent nuclei, cytoplasm occupying most of the capsular space (Fig. 4d), delayed fed larvae had some nuclei condensed at several degrees, cytoplasm frequently reduced, occupying only a small portion of the capsular space, chondrocytes moderately shrunk (Fig. 4e) and starved larvae showed condensed nuclei; cytoplasm often absent or severely reduced and chondrocytes shrunk (Fig. 4f). Fed larvae showed compact muscle fibers and myofibrils striated and compact (Fig. 4g), delayed fed larvae with muscle fibers slightly separated and myofibrils with some loss of striation and separation, nuclear staining variable, often indistinct (Fig. 4h) and starved larvae had pronounced fiber separations and nuclei were dark and indistinct (Fig. 4i). Fed and delayed fed larvae 
Table 1. Mean values of morphometrical variables and Standard deviation (SD) at four and nine days after hatching (DAH) of Pagrus pagrus larvae from the different feeding treatments. \% reduction: difference between mean values of a certain variable obtained four DAH minus the corresponding to nine DHA, and expressed as a percentage; negative percentage means an increase in the mean value of a certain morphometrical variable. BDA: body depth at the anus, ED: eye diameter, HD: head depth, SL: standard length. T1: without food, T2: delayed feeding and T3: fed.

\begin{tabular}{|c|c|c|c|c|c|c|c|c|}
\hline & \multirow{2}{*}{$\begin{array}{c}\text { Variable } \\
(\mu \mathrm{m})\end{array}$} & \multicolumn{3}{|c|}{4 DAH } & \multicolumn{3}{|c|}{$9 \mathrm{DAH}$} & \multirow{2}{*}{$\begin{array}{c}\% \\
\text { reduction }\end{array}$} \\
\hline & & $\mathrm{N}$ & Mean & SD & $\mathrm{N}$ & Mean & SD & \\
\hline \multirow{4}{*}{$\mathrm{T} 1$} & SL & 16 & 2629.52 & 390.24 & 5 & 2282.80 & 376.06 & 13.19 \\
\hline & ED & 16 & 222.14 & 16.01 & 5 & 219.39 & 12.40 & 1.24 \\
\hline & BDA & 16 & 187.58 & 15.89 & 5 & 154.50 & 0.00 & 17.64 \\
\hline & HD & 16 & 544.77 & 84.86 & 5 & 468.00 & 31.84 & 14.09 \\
\hline \multirow{4}{*}{$\mathrm{T} 2$} & SL & 11 & 2468.69 & 427.97 & 10 & 2725.59 & 278.29 & -10.41 \\
\hline & ED & 11 & 225.40 & 22.44 & 10 & 236.22 & 20.60 & -4.80 \\
\hline & $\mathrm{BDA}$ & 11 & 187.85 & 19.89 & 10 & 172.40 & 18.79 & 8.22 \\
\hline & $\mathrm{HD}$ & 11 & 534.51 & 99.33 & 10 & 569.26 & 76.13 & -6.50 \\
\hline \multirow{4}{*}{$\mathrm{T} 3$} & $\overline{S L}$ & 9 & 2532.65 & 377.33 & 9 & 3003.56 & 240.58 & -18.59 \\
\hline & ED & 9 & 219.21 & 20.12 & 9 & 252.87 & 15.36 & -15.36 \\
\hline & BDA & 9 & 187.16 & 9.27 & 9 & 237.38 & 56.86 & -26.83 \\
\hline & HD & 9 & 527.95 & 83.40 & 9 & 641.51 & 87.16 & -21.51 \\
\hline
\end{tabular}

showed no separation between notochord and musculature (Fig. $4 \mathrm{j}, \mathrm{k}$ ) and starved larvae showed slight notochord shrinkage and separation with muscular trunk (Fig. 41).

Mean HCI obtained employing starved larvae resulted significantly lower than those obtained from the other treatments $(P<0.001, \mathrm{~F}=26.59, \mathrm{H}=39.43, \mathrm{n}=69, \mathrm{df}=65)$. Delayed feeding larvae showed a reduction in their mean HCI, significant differences were found with larvae from fed treatment only by means of non parametric multiple comparisons, no differences were observed by means of the Turkey's test (Table 3). As previously mentioned for morphometrical studies, initial condition of larvae (T0) was also included for comparisons.

Daily evolution of mean HCI obtained employing larvae from the different feeding treatments showed that mean HCI of starved larvae decayed from four DAH when food was not supplied (Fig. 5). Mean HCI of larvae from delayed feeding treatment also decayed since four DAH, but later increased since food was supplied six DAH. At seven DAH larvae from treatment two reached HCI mean values close to those obtained employing fed larvae. Fed larvae showed HCI mean values close to three (healthy) during the whole experiment.

Table 2. Results from the PCA on Pagrus pagrus larvae, the eigenvectors (Evc), eigenvalues, percent of the variance explained of the original data set (r2), and correlation (r) of the original variables with the first two principal components, based upon normalized morphometrical variables (indicated as $-\mathrm{N}$ ): head depth (HD), body depth at the anus (BDA) and eye diameter (ED).

\begin{tabular}{ccccc}
\hline & \multicolumn{2}{c}{ PC 1 } & \multicolumn{2}{c}{ PC 2 } \\
\cline { 2 - 6 } & $\mathrm{r}$ & Evc & $\mathrm{r}$ & Evc \\
\hline HD-N & 0.91 & 0.60 & -0.02 & -0.03 \\
BDA-N & 0.85 & 0.57 & -0.46 & -0.68 \\
ED-N & 0.84 & 0.56 & 0.49 & 0.73 \\
\hline Eigenvalue & \multicolumn{2}{c}{2.26} & \multicolumn{2}{c}{0.46} \\
$\mathrm{r}^{2}$ & \multicolumn{2}{c}{75} & \multicolumn{2}{c}{16} \\
\hline
\end{tabular}

Until six DAH no significant differences were found between larval histological condition from the different feeding treatments. After four days of starvation (seven DAH), larvae from $\mathrm{T} 1$ showed a significant lower condition than those from T2 and T3. HCI obtained from starved larvae showed a constant reduction until nine DAH when they reached a minimum mean value of $1.25 \pm 0.11$ and later they experimented mass mortality. Note that non parametric test allowed finding differences between feeding treatments since six DHA. On the other hand, ANOVA showed differences from seven DAH (see multiple comparisons results, Fig. 5).

Delayed feeding larvae showed a mean HCI reduction at five DAH, but since food was provided at six DAH they rapidly recovered from the starvation suffered. Mean HCI obtained employing larvae from $\mathrm{T} 2$ were not significantly different from the corresponding to fed larvae along the entire experiment.

Short term HCI allowed finding statistical differences between mean values obtained employing larvae from the feeding treatments $(P<0.001, \mathrm{~F}=41.03, \mathrm{H}=38.81, \mathrm{n}=66, \mathrm{df}=63)$. On the other hand long term or mean $\mathrm{HCI}$ only showed differences between $\mathrm{T} 1$ and the other two treatments (Fig. 6). Equal results were obtained from parametrical and non parametrical comparisons.

Short term tissues proved to be more sensitive to starvation than long term ones since only 24 hours of starvation were translated in a significant reduction of mean HCI calculated employing those tissues (Fig. 7). In contrast, HCI obtained employing long term tissues showed a reduction only under an extreme starvation. Long term tissues (muscle, notochord, cartilage and nervous system) of partially starved larvae did not show histological changes. Well fed larvae did not show changes on their histological tissues aspect during the experiment.

\section{Discussion}

Morphological development of red porgy larvae was described by Machinandiarena et al. (2003). They found that mouth opening takes place between three and four DAH in 

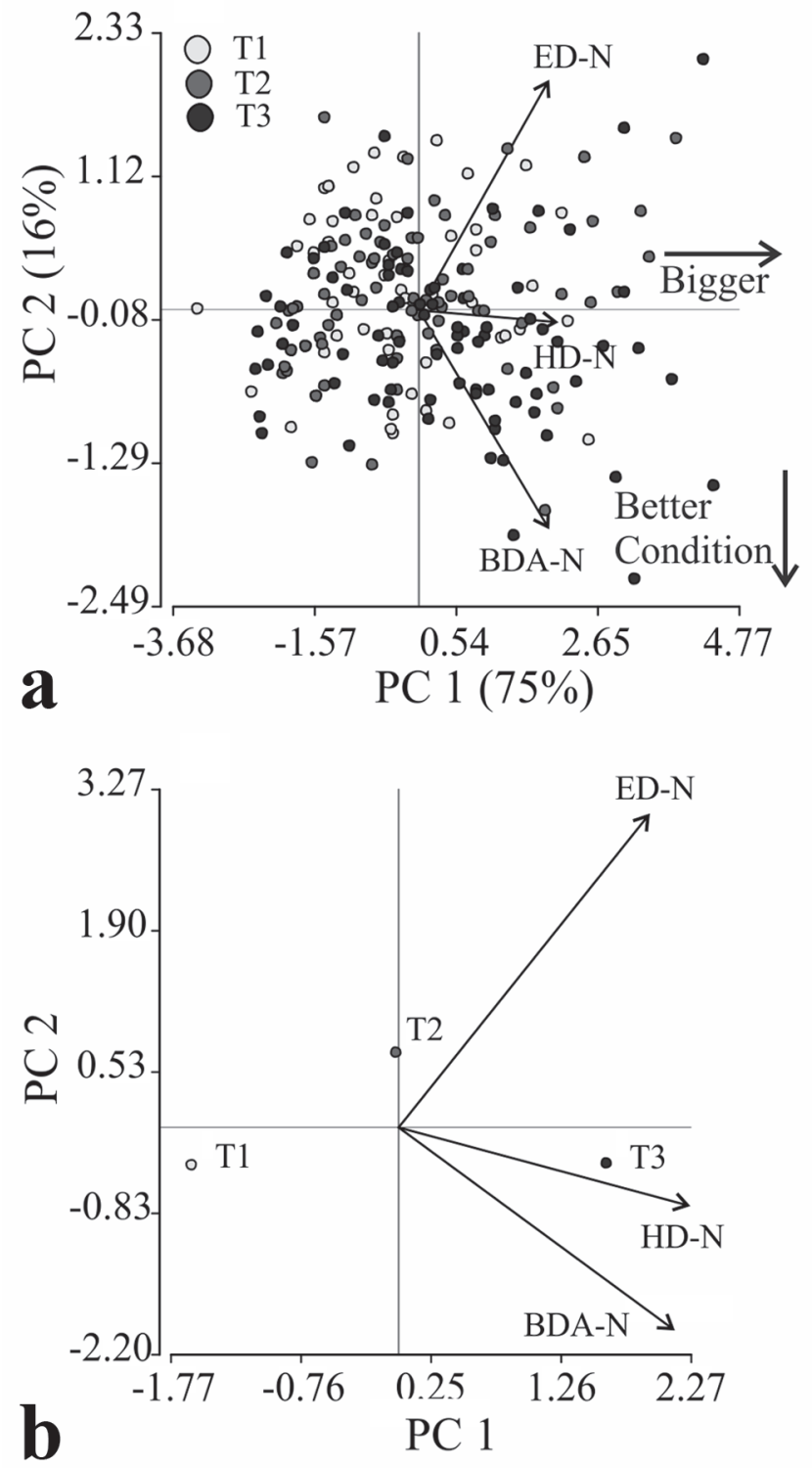

Fig. 2. Scatterplot of PC2 on PC1 for Pagrus pagrus larvae from the feeding treatments. a: PCA based upon normalized morphometrical variables; $\mathbf{b}$ : PCA based upon normalized morphometrical variables and observations grouped by feeding treatments. Correlations between the variables also showed. BDA: body depth at the anus, ED: eye diameter, HD: head depth. T1: without food, T2: delayed feeding and T3: fed. $-\mathrm{N}$ indicates normalized morphometrical variables.

coincidence with the exhaustion of yolk reserves using the same methodologies and rearing protocol herein employed.

Transition to external feeding represents one of the critical events during fish larvae ontogenetic development. Growth and developmental patterns depend on environmental conditions, such as temperature or appropriate food availability, and individual constitution, as for example the amount of yolk in newly hatched larvae. The lack of food is translated into different degree of cellular and tissular alterations according to the starvation suffered. Also, different tissues respond in different way to food deprivation (Uriarte \& Balbontín, 1987).

Red porgy larvae have a small yolk sac. Thus, feeding should start soon after hatching. This requires a fast development of different structures and tissues related to prey capture and digestion (Roo et al., 1999). Complete yolk exhaustion was observed between three to four DAH at $18^{\circ} \mathrm{C}$ of rearing temperature, in coincidence with previous studies made by Machinandiarena et al. (2003), Aristizábal \& Suárez (2006) and Aristizábal et al. (2009). Starved larvae survived up to nine DAH, when a mass mortality was observed. Similar results were obtained by Yúfera et al. (1993) employing Sparus aurata larvae reared at $19^{\circ} \mathrm{C}$ and Dou et al. (2002) employing Paralicthys olivaceus larvae reared at $17^{\circ} \mathrm{C}$. But as has been demonstrated in several studies, toleration to starvation and larval survival is strongly influenced by rearing temperature (McGurk, 1984, Dou et al., 2005). Delayed feeding larvae recovered after starvation but did not reach fed larvae sizes until the end of the experiment $11 \mathrm{DAH}$.

Roo et al. (1999) studied gut and eye development employing porgy larvae and they found that mouth opening took place simultaneously with yolk exhaustion three DAH at $20-21^{\circ} \mathrm{C}$. But larvae did not start external feeding until four DAH when visual system is completely ready for prey capture. At that moment gut digestive activity started and gut content became evident. According to those results, we found a reduction in body depth three DAH. Thus, when yolk sac is exhausted porgy larvae normally suffer a short starvation period until gut and visual system are functional. When larvae reach four DAH, their ability to capture prey increases dramatically (Roo et al., 1999). Therefore, during our investigation, fed larvae showed a constant increment in all measured morphometrical variables from four DAH. Larvae from delayed feeding treatment showed a recovery since nine $\mathrm{DAH}$, that is, three days after food became available.

From the studied morphometrical variables, body depth turned out to be the most responsive to starvation. Similar results were obtained when comparing morphometrical variables from fed and starved larvae by Yufera et al. (1993) for S. aurata. Dou et al.(2002) for P. olivaceus and Bustos \& Silva (2011) for Seriolella violacea. This variable reflects muscular tissue stored energy, as the body width depends largely on the cumulative amount of muscle fibers. Yúfera et al. (1993) demonstrated that starved $S$. aurata larvae obtain energy from the consumption of muscular tissue. After exhaustion of lipid reserves, stored as triacylglycerols, larvae begin to use stored fat reserves in muscle tissue and under extreme starvation might use their proteins. In addition, several studies employing morphometrical variables also highlighted the sensitivity of body height to starvation (Ehrlich et al., 1976; Theilacker, 1978; Powell \& Chester, 1985; Uriarte \& Balbontín, 1987).

We observed an important reduction in the mean standard length of starved larvae ( $13 \%$ between four and nine DHA at $18^{\circ} \mathrm{C}$ ), indicating that this variable also responded strongly to starvation. Supporting our results, Gisbert et al. (2004) 

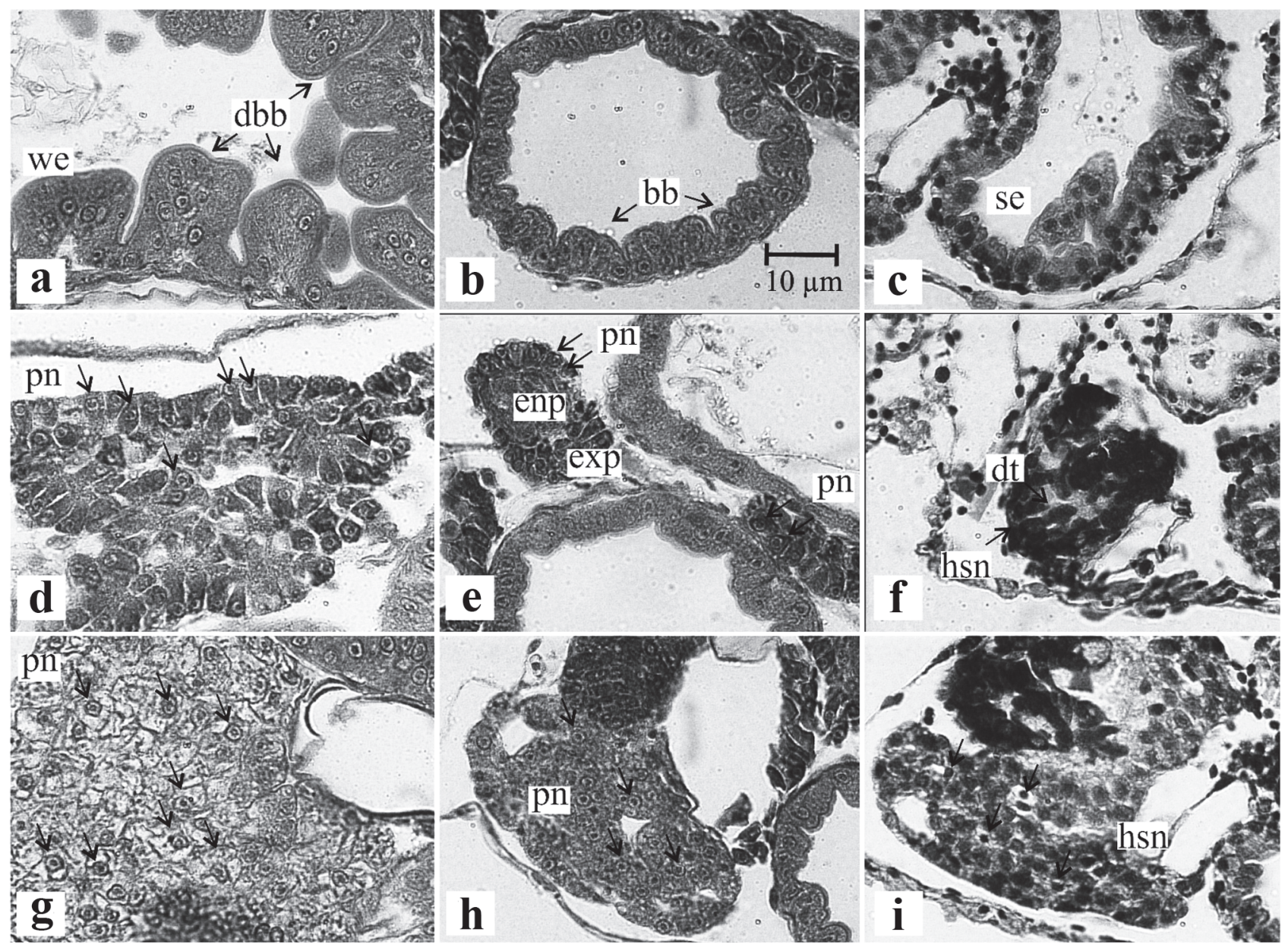

Fig. 3. Histological sections of Pagrus pagrus larvae, indicators of short term nutritional condition. Sagital section of $4 \mu \mathrm{m}$ thick stained with Harris's hematoxylin and eosin counterstain (H-E). (a-c) digestive duct, (d-f) pancreas, (g-i) liver; left $=$ fed larvae, middle $=$ delayed fed lavae and right $=$ starved larvae. $b b$ : brush border, dbb: distinct brush border, dt: dissociated tissue, enp: endocrine pancreas, exp: exocrine pancreas, hsn: heavily stained nucleus, pn: prominent nucleus, se: shrunken enterocytes, we: wide enterocytes. Scale bar indicates $10 \mu \mathrm{m}$.

found approximately $7 \%$ reduction in standard length between 4 and 7 DHA employing P. californicus larvae also reared at $18^{\circ} \mathrm{C}$. The least responsive to starvation morphometrical variable was the eye diameter. In contrast to other variables, eye diameter showed a continuous increase throughout the experiment in both fed and starved larvae. Roo et al. (1999) have found high correlations between larval total length and eye diameter. These authors have suggested that size increase and visual system development would improve their swimming ability allowing prey capture, as well as identifying and escaping from predators.

As observed by Dou et al. (2002) employing P. olivaceus, head height, also showed a positive increment throughout the experiment also proving to be a sensitive indicator of starvation. Probably, visual system and head development are a priority in terms of energy allocation in comparison with the development of other structures. It is common in most fish species to observe the development of the anterior and posterior body regions prior to the abdominal part. This ensures that the essential organs for primary functions such as feeding, respiration and locomotion, are developed first (Osse \& van den Boogaart, 1995).

The use of normalized morphometrical variables in the PCA showed shape differences among red porgy larvae reared under different feeding conditions.

Multivariate analysis is one of the best techniques that allows the study of several variables from individuals as a whole to determine affinities between those individuals. McGurk (1985) stated that only PCA satisfies the requirements of the ideal morphometric factor: size-independence; biological meaning and orthogonality. Another advantage of this technique is that it opens the possibility of assessing wild larvae where nutrition and development is unknown (Cunha et al., 2003). Although the main drawback of this technique is the influence of size due to allometric growth, in order to guaranty that shape variations are only reflecting larval nutritional status, in the present study, data were normalized according to Lleonart et al. (2000) method. The main advantage of using morphometrical variables is that they 

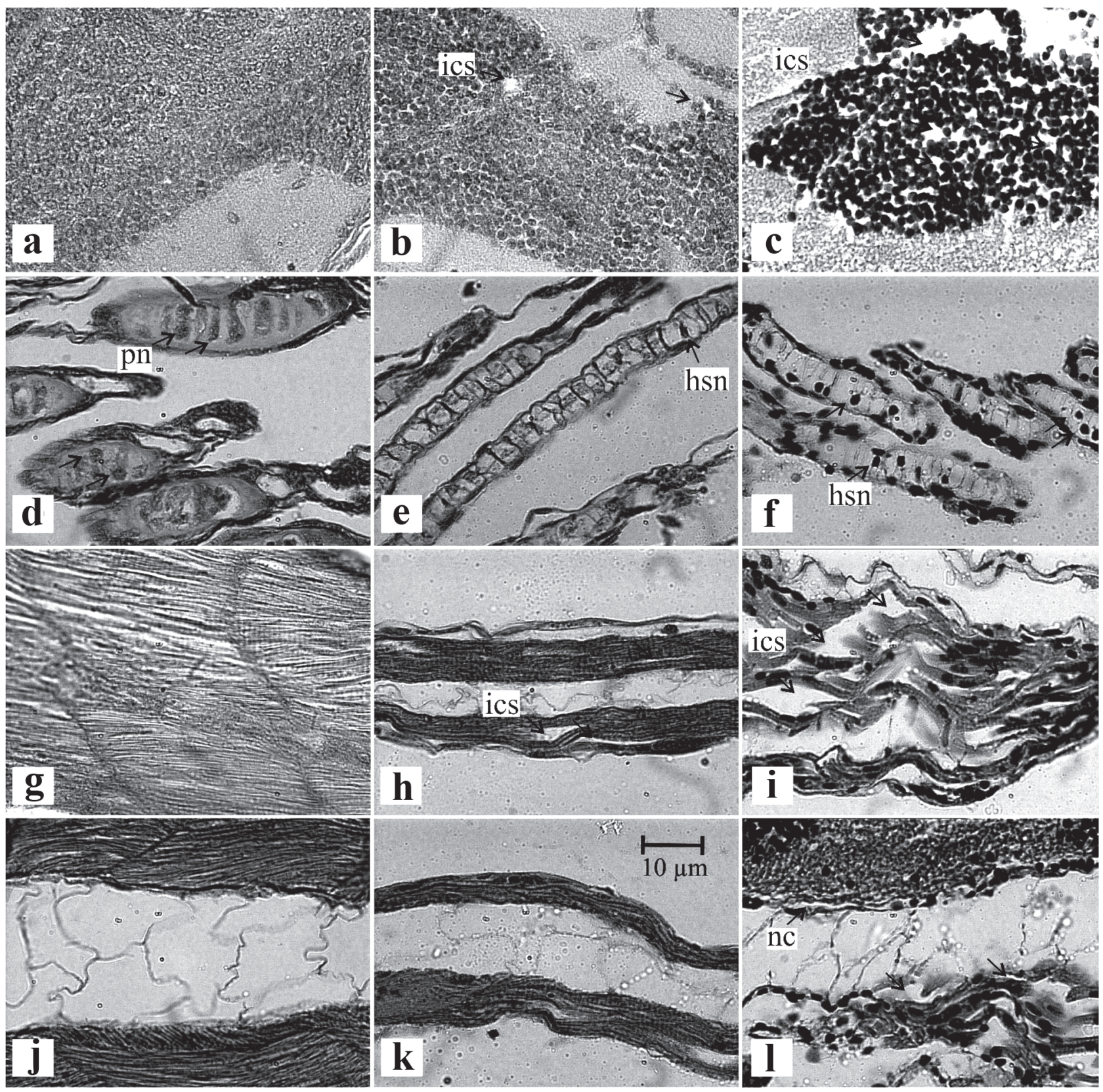

Fig. 4. Histological sections of Pagrus pagrus larvae, indicators of long term nutritional condition. Sagital section of $4 \mu \mathrm{m}$ thick stained with Harris's hematoxylin and eosin counterstain (H-E). (a-c) nervous system, $(\mathbf{d}-\mathbf{f})$ cartilage, $(\mathbf{g}-\mathbf{i})$ muscle, $(\mathbf{j}-\mathbf{l})$ notochord; left $=$ fed larvae, middle $=$ delayed fed larvae and right $=$ starved. hsn: heavily stained nucleus, ics: inter-cellular space, nc: notochord contraction, pn: prominent nucleus. Scale bar indicates $10 \mu \mathrm{m}$.

are simple and easy to assess. However, the individual variability of morphometry in wild larvae make difficult to set thin boundaries between healthy and starved larvae.

Results herein presented, gave evidence that red porgy larvae, after four days of food deprivation, experienced a significant reduction on their histological condition.

The indicative value of extreme starvation was $1.25 \pm 0.11$ of mean HCI, which was obtained around the sixth day of food deprivation when a mass mortality was registered. We believe that this minimum HCI value can be associated with the "point of irreversible starvation" or "point of no return" (PNR), which has an inherent maximum associated probability of death. On the other hand, delayed feeding larvae (which experienced three days of food deprivation) showed a complete recovery and could not be distinguished from fed larvae.

Analyzed tissues displayed different response time to starvation, as it has been observed in several species reared in laboratory in previous studies (Kashuba \& Matthews, 1984; 
Table 3. Mean and median histological condition index (HCI) and standard deviation (SD) for Pagrus pagrus larvae from the feeding treatments. Different lowercase letters indicate significant differences $(p<0.001)$ among feeding treatments, after one way ANOVA followed by post-hoc Tukey's test and different capital letters indicate significant differences after Kruskal-Wallis test followed by multiple comparisons. T0: before the experiment begins, T1: without food, T2: delayed feeding and T3: fed.

\begin{tabular}{ccccccc}
\hline Treatment & N & Mean & SD & Median & $\begin{array}{c}\text { ANOVA, Tukey } \\
F=26.59 ; \\
\mathrm{P}<0.001\end{array}$ & $\begin{array}{c}\text { Kruskal Wallis } \\
H=39.43 ; \\
\mathrm{P}<0.001\end{array}$ \\
\hline T0 & 3 & 2.93 & 0.06 & 2,90 & $\mathrm{~b}$ & $\mathrm{BC}$ \\
$\mathrm{T} 1$ & 17 & 2.01 & 0.64 & 1.83 & $\mathrm{a}$ & $\mathrm{A}$ \\
$\mathrm{T} 2$ & 26 & 2.78 & 0.22 & 2.85 & $\mathrm{~b}$ & $\mathrm{~B}$ \\
$\mathrm{~T} 3$ & 23 & 2.95 & 0.09 & 3.00 & $\mathrm{~b}$ & $\mathrm{C}$ \\
\hline
\end{tabular}

Theilacker, 1986). Long term tissues (muscle, notochord, cartilage, and nervous system) only showed histological changes under extreme starvation suffered from starved treatment larvae and only few studies have analyzed their response to starvation (O’Connell, 1976; Uriarte \& Balbontín, 1987; Pizarro et al., 1998; Catalán \& Olivar, 2002; Catalán, 2003). On the other hand, short term tissues (gut, liver, and pancreas) have been widely used and probed to be more sensitive to starvation than long term tissues (Sieg, 1998; Chen et al., 2007; Diaz et al., 2011). Gisbert et al. (2004) found that after two days of food deprivation $P$. californicus larvae showed a significant reduction in height of gut epithelial cells. In the present study, even though only qualitative analysis has been performed, histological changes were evident only 24 hours since starvation started in both starved and delayed feeding treatments.

Internal and chemical composition changes that occur in fish organ systems under starvation conditions have been

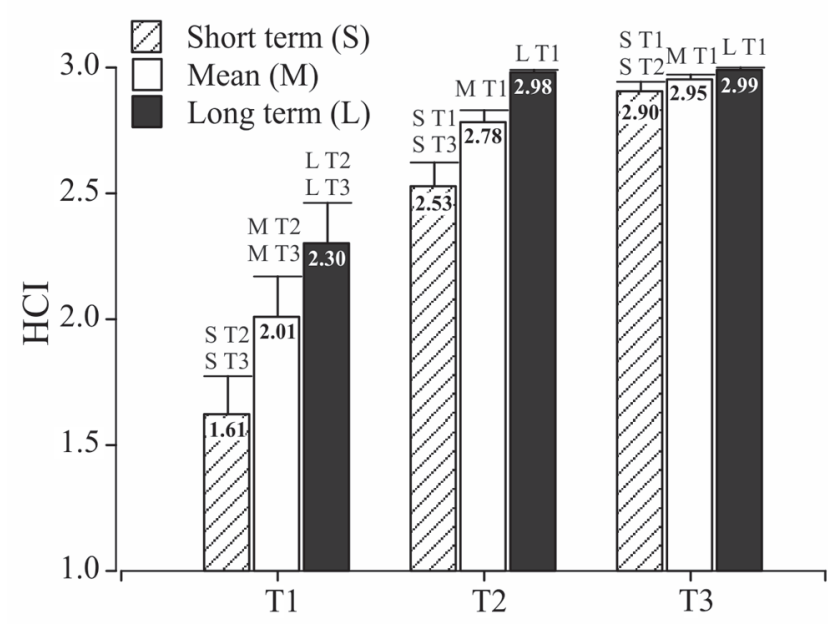

Fig. 6. Mean histological condition index (HCI) and standard error for Pagrus pagrus larvae from the feeding treatments calculated employing short or long term tissues and a mean value employing all tissues. Different letters indicate significant differences $(\mathrm{p}<0.05)$ among feeding treatments, after one way ANOVA followed by post-hoc Tukey's test. T1: without food, T2: delayed feeding and T3: fed, S: short term HCI, M: mean HCI, L: long term HCI.

reviewed by Love (1970). This study and subsequent research, such as Johnston \& Goldspink (1973) and Stirling (1976), showed that during starvation there is a reduction in the storage substances and an increase in water content. Rapid changes can also occur in the digestive tract and liver. Nervous system appears to be the last to show changes under food deprivation (Ehrlich et al., 1976). The mobilization of reserve substances appears to be a controlled process in early developmental

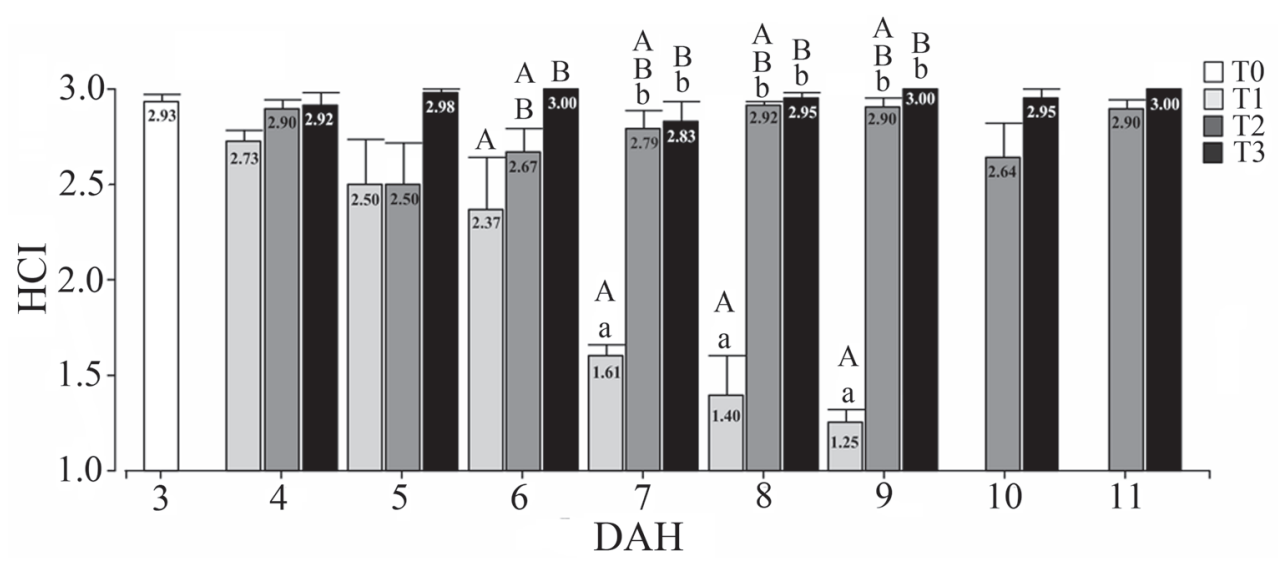

Fig. 5. Mean histological condition index (HCI) and standard error for Pagrus pagrus larvae from the feeding treatments against larval age expressed as days after hatching (DAH). Different lowercase letters indicate significant differences $(\mathrm{p}<0.05)$ among feeding treatments, after one way ANOVA followed by post-hoc Tukey's test. Different capital letters indicate significant differences $(\mathrm{p}<0.05)$ among feeding treatments, after Kruskal Wallis test followed by multiple comparisons. T0: before the experiment begins, T1: without food, T2: delayed feeding and T3: fed. 


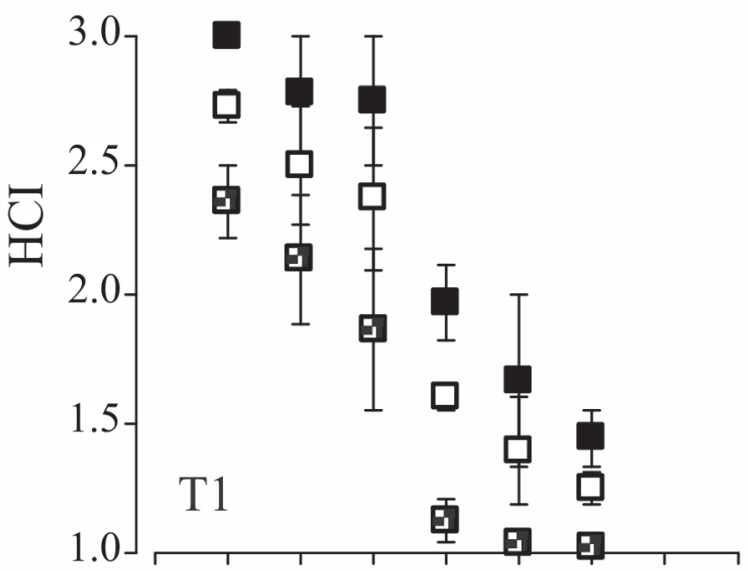

$\mathbf{a}$

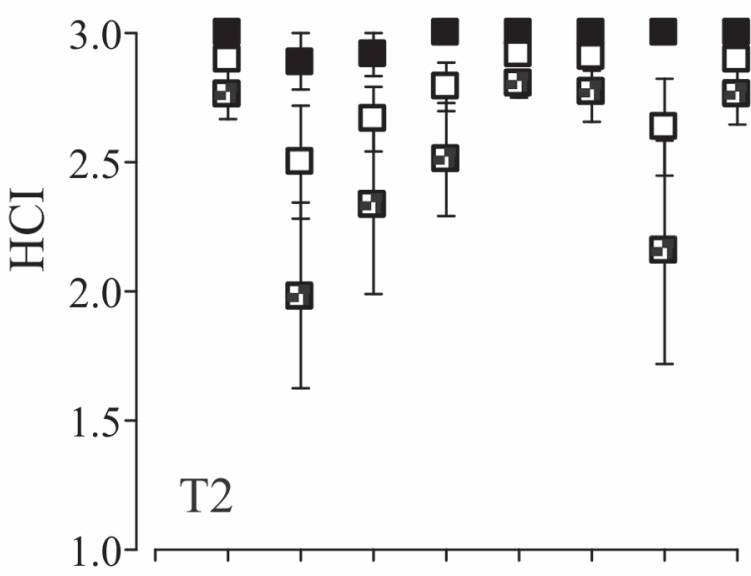

b

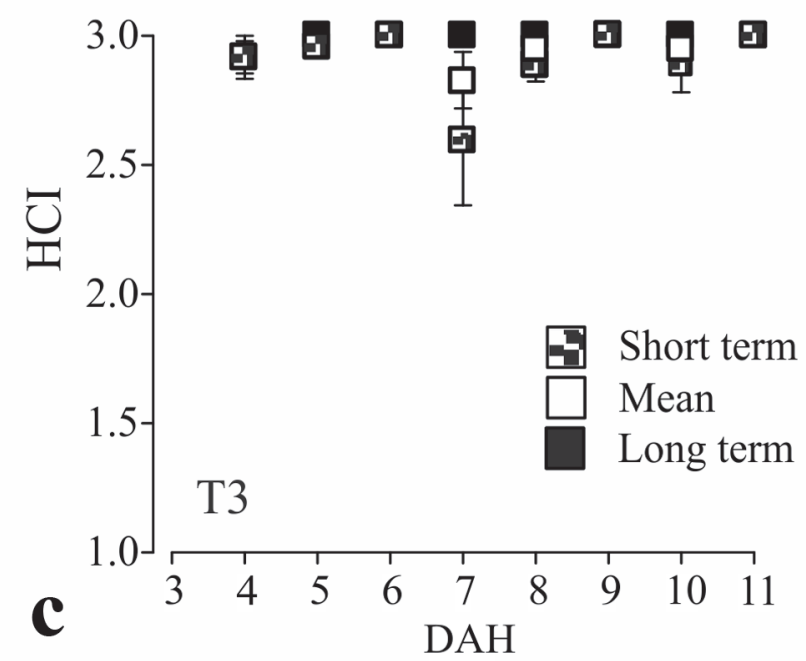

Fig. 7. Mean histological condition index (HCI) and standard error for Pagrus pagrus larvae calculated employing short or long term tissues and a mean value employing all tissues against larval age expressed as days after hatching (DAH) from the feeding treatments, a: without food (T1); b: delayed feeding (T2); c: fed (T3). stages, showing a conservation of the most important organs for survival and the locomotor system, which are only consumed under extreme starvation. Thus, it is expected that the immediate response to starvation is translated into changes at the digestive system and accessory glands. Several studies have revealed that starved larvae showed a reduction in their intestinal epithelial cells height and the amount of connective tissue (Kostomarova, 1962; Ehrlich et al., 1976; Theilacker \& Watanabe, 1989; Gisbert et al., 2004). The reduction of liver size under starvation demonstrated its importance as a storage organ (Love, 1970; Ehrlich, 1972).

Nowadays, histological techniques represent valuable tools to acquire reliable information on larval nutritional condition. Histological study can be focused on tissues that reflect more accurately variations in larval condition of a certain species, or developmental stage, according to the particular objectives of the study.

One of the main problems of this methodology, apart from the huge amount of time required to be performed, is the low objectivity since measures are mainly qualitative (O'Connell, 1980; McFadzen et al., 1997) and the variability introduced by the scientist's experience (Ferron \& Leggett, 1994). Lately, digital image analysis is becoming popular in nutritional condition studies. These tools permit accurate quantification (for example, cellular areas or volumes) that allows statistical analysis. However, Catalán (2003) compared quantitative and qualitative measurements on larvae from experimental starvation treatments and stated that qualitative indices allow a correct classification of the individuals in the majority of the cases and in different developmental stages. These results were explained on the basis that qualitative studies take into consideration more cellular or tissular attributes, than quantitative ones. However, studies involving both morphometrical variables and quantitative histological measurements (such as intestinal epithelial cells height) and multivariate analysis could be very useful and accurate for nutritional condition assessment (Gisbert et al., 2004).

Mechanisms of population control have been an important focus of inquiry in fisheries research. The assessment of factors that determine abundance is complex since many of them may act simultaneously. It is known that populations' dynamics of fish are affected by the influence of environmental conditions. Even though it is under discussion at which developmental stage recruitment is determined, larval mortality is still considered very important in this concern. Factors affecting survival of young fish are diverse. Many authors agree that main sources of mortality are predation and starvation (Bailey \& Houde, 1989).

Hewitt et al. (1985) demonstrated that predation was the major source of mortality of yolk-sac Trachurus symmetricus larvae. As the yolks were absorbed and the larvae began to feed, starvation became a significant source of mortality. As the larvae further developed, starvation rapidly declined and predation again became the dominant source of mortality, although at a much lower rate. However, the exact importance of starvation-mortality in the field is unclear. Results are often contradictory and highly species-specific. Ferron and Leggett 
(1994) concluded that most studies fail to establish any clear relationship between field-determined starvation and larval survival. For this reason, the study of this coupling in the laboratory must be undertaken when possible.

One of the main problems when comparing reared and wild larvae is that some morphological changes can be induced by rearing conditions. Growth rates may also vary as a result of type of food or to confinement tanks characteristics (Ehrlich et al., 1976). In this concern, histological study of certain tissues that probed to be sensitive to starvation seems more reliable when comparing wild and laboratory-reared larvae. Still, several studies showed that morphometrical and histological techniques proved to be successful to identify starved larvae in both wild and laboratory (O'Connell, 1980; Kashuba \& Matthews, 1984; Hewitt et al., 1985; Theilacker, 1986).

As previously discussed, it is clear that in order to determine the incidence of starvation in the sea, laboratory calibrations are necessary, taking into account and trying to minimize the possible sources of variability introduced (Clemmesen, 1994). The main objective of these laboratory calibrations is to infer the potential of survival in the ocean and, eventually, estimate the likelihood of these individuals to recruit to fisheries.

Finally, the methodologies presented here have proven to be sufficiently sensitive and could be used in tank-reared larvae in order to calibrate the different degrees of starvation in the sea or to determine the quality of larvae produced in aquaculture. This will serve to evaluate the effects of changes in breeding protocols or the type of food provided, in order to improve survival in early stages of development.

\section{Acknowledgments}

We wish to thank Marcela De Falco for her valuable comments on the manuscript. We also would like to thank INIDEP aquarium personnel for their help during larvae rearing. Special thanks to Julieta Suárez for her help during rearing experiments and Ernesto Christiansen for his help during histological procedures. Our thanks are also extended to our anonymous reviewers for their improvements and useful suggestions. This work was supported by the INIDEP and the CONICET. This is INIDEP contribution $N^{\circ} 1792$.

\section{Literature Cited}

Aristizábal, E. O. \& J. Suárez. 2006. Efficiency of co-feeding red porgy (Pagrus pagrus L.) larvae with live and compound diet. Revista de Biología Marina y Oceanografía, 41: 203-208.

Aristizábal, E. O., J. Suárez, A. Vega \& R. Bargas. 2009. Egg and larval quality assessment in the Argentinean red porgy (Pagrus pagrus). Aquaculture, 287: 329-334.

Bailey, K. M. \& E. D. Houde. 1989. Predation on eggs and larvae of marine fishes and the recruit problem. Advances in Marine Biology, 25: 1-83.

Bustos, C. \& A. Silva. 2011. Endogenous feeding and morphological changes in hatchery-reared larval palm ruff Seriolella violacea (Pisces: Centrolophidae) under starvation. Aquaculture Research, 42: 892-897.
Catalán, I. A. 2003. Condition indices and their relationship with environmental factors in fish larvae. Unpublished Ph.D. Dissertation, Universitat de Barcelona, Barcelona, 265p.

Catalán, I. A. \& M. P. Olivar. 2002. Quantification of muscle condition using digital image analysis in Dicentrarchus labrax larvae, and relationship with survival. Journal of the Marine Biological Association of the United Kingdom, 82: 649-654.

Chen, N. B., J. G. Qin, J. F. Carragher, S. M. Clarke, M. S. Kumar \& W. G. Hutchinson. 2007. Deleterious effects of food restrictions in yellowtail kingfish Seriola lalandi during early development. Aquaculture, 271: 326-335.

Clemmesen, C. 1994. The effect of food availability, age or size on the RNA/DNA ratio of individually measured herring larvae: laboratory calibration. Marine Biology, 118: 377-382.

Clemmesen, C. M., R. P. Sánchez \& C. Wongtschowski. 1997. A regional comparison of nutritional condition of SW Atlantic anchovy larvae (Engraulis anchoita) based on RNA/DNA ratios. Archive of Fishery and Marine Research, 45: 17-43.

Cotrina, C. 1989. Estudio biológico del besugo (Pagrus pagrus) del Ecosistema Costero

Bonaerense. Unpublished Ph.D. Dissertation, Universidad de Buenos Aires, Buenos Aires, 140p.

Cotrina, C. P. \& M. C. Raimondo. 1997. Estudio de edad y crecimiento del besugo (Pagrus

pagrus) del sector costero bonaerense. Revista de Investigación y Desarrollo Pesquero, 11: 95-118.

Cunha, I., F. Saborido-Rey \& M. Planas. 2003. Use of multivariate analysis to assess the nutritional condition of fish larvae from nucleic acids and protein content. Biological Bulletin, 204: 339-349.

Diaz, M. V. 2010. Análisis espacio-temporal del estado nutricional de larvas de anchoíta Engraulis anchoita. Relación con las características hidrográficas y la disponibilidad de alimento. Unpublished Ph.D. Dissertation, Universidad Nacional de Buenos Aires, Buenos Aires, 282p.

Diaz, M. V., M. Pájaro, M. P. Olivar, P. Martos \& G. J. Macchi. 2011. Nutritional condition of Argentine anchovy Engraulis anchoita larvae in connection with nursery ground properties. Fisheries Research, 109: 330-341.

Dou, S. Z., R. Masuda, M. Tanaka \& K. Tsukamoto. 2002. Feeding resumption, morphological changes and mortality during starvation in Japanese flounder larvae. Journal of Fish Biology, 60: 1363-1380.

Dou, S. Z., R. Masuda, M. Tanaka \& K. Tsukamoto. 2005. Effects of temperature and delayed initial feeding on the survival and growth of Japanese flounder larvae. Journal of Fish Biology, 66: 362-377.

Ehrlich, K. F. 1972. Morphometrical, behavioural and chemical changes during growth and starvation of herring and plaice larvae. Unpublished Ph.D. Dissertation, Stirling University, Scotland, 132p.

Ehrlich, K. F., J. H. S. Blaxter \& R. Pemberton. 1976. Morphological and histological changes during the growth and starvation of herring and plaice larvae. Marine Biology, 35: 105-118.

Ferron, A. \& W. C. Leggett. 1994. An appraisal of condition measures for marine fish larvae. Advances in Marine Biology, 30: 217-303.

Frank, K. T. \& J. K. McRuer. 1989. Nutritional status of fieldcollected haddock (Melanogrammus aeglefinus) larvae from Southwestern Nova Scotia: an assessment based on morphometric and vertical distribution data. Canadian Journal of Fisheries and Aquatic Sciences, 46: 125-133.

Gisbert, E., J. B. Ortiz-Delgado \& C. Sarasquete. 2008. Nutritional cellular biomarkers in early life stages of fish. Histology and histopathology, 23: 1525-1539. 
Håkanson, J. L. 1989 Analysis of lipid components for determining the condition of anchovy larvae, Engraulis mordax. Marine Biology, 102: 143-151.

Harris, P. J. \& J. C. McGovern. 1997. Changes in the life history of red porgy, Pagrus pagrus, from the southeast United States, 1972-1994. Fishery Bulletin, 95: 732-747.

Hewitt, R., G. Theilacker \& N. C. Lo. 1985. Causes or mortality of young jack mackerel. Marine Ecology Progress Series, 26: 1-10.

Hunter, J. R. 1981. Feeding ecology and predation of marine fish larvae. Pp. 33-79. In: Lasker, R. (Ed.). Marine Fish Larvae. Morphology, Ecology and Relation to Fisheries. Washington, Washington Sea Grant Program.

Johnston, I. A. \& G. Goldspink. 1973. Some effects of prolonged starvation on metabolism of the red and white myotomal muscles of the plaice Pleuronectes platessa. Marine Biology, 19: 348-353.

Kailasam, M., A. R. Thirunavukkarasu, S. Selvaraj \& P. Stalin. 2007. Effect of delayed initial feeding on growth and survival of Asian sea bass Lates calcarifer (Bloch) larvae. Aquaculture, 27: 298-306.

Kashuba, S. \& W. J. Matthews. 1984. Physical condition of larval shad during spring-summer in a southwestern reservoir. Transactions of the American Fisheries Society, 113: 119-204.

Kostomarova, A. A. 1962. Effect of starvation on the development of the larvae of bony fishes. Trudy Instituta Morfologii Zhivotnykh, 40: 4-77.

Lleonart J., J. Salat \& G. J. Torres. 2000. Removing allometric effects of body size in morphological analysis. Journal of Theoretical Biology, 205: 85-93.

Love, R. M. 1970. The chemical biology of fishes. Vol.1. Academic press, New York, 547p.

Machinandiarena, L., M. I. Müller \& A. López. 2003. Early life stages of development of the red porgy Pagrus pagrus (Pisces, Sparidae) in captivity, Argentina. Investigaciones Marinas, 31: 5-13.

Manooch, C. S. 1976. Reproductive cycle, fecundity, and sex ratios of the red porgy,

Pagrus pagrus (Pisces: Sparidae) in North Carolina. Fishery Bulletin, 74: 775-781.

Maragoudaki, D., M. Paspatis \& M. Kentouri. 1999. Influence of stocking density on growth of juvenile red porgy Pagrus pagrus L. under different feeding conditions. Aquaculture Research, 30: 501-508.

McFadzen, I. R. B., S. H. Coombs \& N. C. Halliday. 1997. Histological indices of the nutritional condition of sardine, Sardina pilchardus (Walbaum) larvae off the north coast of Spain. Journal of Experimental Marine Biology and Ecology, 212: 239-258.

McGurk, M. D. 1984. Effects of delayed feeding and temperature on the age of irreversible starvation and on the rates of growth and mortality of Pacific herring larvae. Marine Biology, 84: 13-26.

McGurk, M. D. 1985. Multivariate analysis of morphometry and dry weight of Pacific herring larvae. Marine Biology, 86: 1-11.

O'Connell, C. P. 1976. Histological criteria for diagnosing the starving condition in early post yolk sac larvae of the northern anchovy, Engraulis mordax Girard. Journal of Experimental Marine Biology and Ecology, 25: 285-312.

O'Connell, C. P. 1980. Percentage of starving northern anchovy, Engraulis mordax, larvae in the sea as estimated by histological methods. Fishery Bulletin, 78: 475-489.

Osse, J. W. M. \& J. G. M. van den Boogaart. 1995. Fish larvae, development, allometric growth, and the aquatic environment. ICES Marine Science Symposia, 201: 21-34.

Pajuelo, G. C. \& J. M. Lorenzo. 1996. Life history of the red porgy
Pagrus pagrus (Teleostei: Sparidae) of the Canary Islands, central east Atlantic. Fisheries Research, 28: 163-177.

Pizarro, J., W. Palma \& C. Flores. 1998. Validación de la hipótesis de mortalidad por inanición en larvas de Engraulis ringens Jenyns, 1842 (Pisces: Engraulidae), utilizando el criterio histológico en un área de surgencia costera en el norte de Chile. Investigaciones Marinas 26: 97-108.

Powell, A. B. \& A. J. Chester. 1985. Morphometric indices of nutritional condition and sensitivity to starvation of spot larvae. Transactions of the American Fisheries Society, 114: 338-347.

Roo, F. J., J. Socorro, M. S. Izquierdo, M. J. Caballero, C. M. Hernández-Cruz, A. Fernández \& H. Fernández-Palacios. 1999. Development of red porgy Pagrus pagrus visual system in relation with changes in the digestive tract and larval feeding habits. Aquaculture, 179: 499-512.

Schuchardt, D., J. M. Vergara, H. Fernández-Palacios, C. T. Kalinowski, C. M. Hernández-Cruz, Izquierdo \& L. Robaina. 2008. Effects of different dietary protein and lipid levels on growth, feed utilization and body composition of the red porgy (Pagrus pagrus) fingerlings. Aquaculture Nutrition, 14: 1-9.

Sieg, A. 1998. A study on the histological classification of the in situ-nutritional condition of larval South-west Atlantic anchovy, Engraulis anchoita Hubbs and Marini, 1935. Archive of Fishery and Marine Research, 46: 19-36.

Stirling, H. P. 1976. Effects of experimental feeding and starvation on the proximate composition of the European bass Dicentrarchus labrax. Marine Biology, 34: 85-91.

Suzer, C., H. Okan Kamachi, D. Coban, S. Saka, K. Firat, B. Özkara \& A. Özkara. 2007. Digestive enzyme activity of the red porgy (Pagrus pagrus, L.) during larval development under culture conditions. Aquaculture Nutrition, 38: 1778-1785.

Theilacker, G. H. 1978. Effect of starvation on the histological and morphological characteristics of jack mackerel, Trachurus symmetricus, larvae. Fishery Bulletin, 76: 403-414.

Theilacker, G. H. 1986. Starvation-induced mortality of young sea-caught jack mackerel, Trachurus symmetricus, determined with histological and morphological methods. Fishery Bulletin, 84: 1-17.

Theilacker, G. H. \& Y. Watanabe. 1989. Midgut cell heigth defines nutritional status of laboratory-raised larval northern anchovy, Engraulis mordax. Fishery Bulletin, 87: 1989-1998.

Uriarte, I. \& F. Balbontín. 1987. Caracterización del estado de hambruna en las larvas de sardina Sardinops sagax musica (Pisces, Clupeiformes) mediante criterios morfométricos e histológicos. Revista de Biología Marina, 23: 77-106.

Vassilopoulou, V. \& C. Papaconstantinou. 1992. Age, growth and mortality of the red porgy, Pagrus pagrus, in the Eastern Mediterranean Sea (Dodecanese, Greece). Vie Milieu, 42: 51-55.

Watanabe, T. \& V. Kiron. 1996. Red sea bream (Pagrus major). Pp. 398-413. In: Bromage, N. \& R. Roberts (Eds.). Broodstock management and egg and larval quality. New York, Blackwell Science.

Yúfera, M., E. Pascual, A. Polo \& M. C. Sarasquete. 1993. Effect of starvation on the feeding ability of gilthead seabream (Sparus aurata L.) larvae at first feeding. Journal of Experimental Marine Biology and Ecology, 169: 259-272.

Submitted December 26, 2012 Accepted June 7, 2013 by Bernardo Baldisserotto Published September 30, 2013 